\title{
Acute type A aortic dissection: the role of frozen elephant trunk
}

\author{
Hitoshi Ogino \\ Department of Cardiovascular Surgery, Tokyo Medical University, Tokyo, Japan \\ Correspondence to: Hitoshi Ogino, MD, PhD. Department of Cardiovascular Surgery, Tokyo Medical University, 6-7-1 Nishishinjuku, Shinjuku-ku, \\ Tokyo 160-0023, Japan. Email: hogino@tokyo-med.ac.jp.
}

Submitted Dec 16, 2019. Accepted for publication Jan 23, 2020.

doi: 10.21037/acs-2019-fet-19

View this article at: http://dx.doi.org/10.21037/acs-2019-fet-19

In this editorial, the current position of frozen elephant trunk (FET) in the open repair of acute type A aortic dissection (AAAD) is described. The standard operating procedures in emergency settings for AAAD, which are "tear-oriented repairs" of aortic resection (i.e., including entry-tear and graft replacement of its aortic segment) have been ascending or hemi-arch replacement, because most primary entry-tears are located in the ascending aorta, and up to the proximal arch, which were resected through the limited repairs. This type of emergency surgery is expected to be sufficiently secure, so as to rescue patients suffering from catastrophic conditions. During the mid-1990s, Kato et al. innovated a novel graft-implanting technique named "open stent graft (OSG)" for aortic dissections, as well as non-dissecting aneurysms, with a home-made stent graft (1). However, in the 2000s, in order to obtain more favorable long-term outcomes, prompt total arch replacement (TAR) was recommended in some candidates with arch-toproximal-descending entry-tear, severely dissected arch/ arch-vessels, a dilated arch, down-stream malperfusion, relatively young age, and so on $(2,3)$.

At the time, the TAR procedure itself had been relatively standardized with favorable outcomes based on more experiences and secure brain-protection techniques. In most cases, conventional elephant trunk (ET) was used for reinforcement of the distal anastomosis as well as early closure of the distal false lumen of the descending aorta. In our series, favorable outcomes were achieved upon closure of the false lumen in the proximal to mid-descending aorta by means of ET (3). However, some technical difficulties were encountered with respect to insertion of non-stented ETs to the narrowed true channel, with fragile dissecting flaps. In some instances, a smaller (16 or $18 \mathrm{~mm}$ ) diameter ET managed to be inserted, particularly, in young patients, including cases of Marfan syndrome.

Following the initial concept by Kato, Ishihara et al. and Uchida et al. had addressed the greater impact of homemade OSG on down-stream aortic remodeling, with the false lumen closed $(4,5)$. After the Japanese surgeons' contributions to this surgical strategy, two European and one Chinese FET devices have been applied clinically (6-8). Since 2014 , in our country, the $4^{\text {th }}$ FET device-initially named Open Stent $\mathrm{Graft}^{\circledR}$ and renamed later to Frozenix ${ }^{\circledR}$ (Japan Lifeline, Tokyo)—has been clinically available. The details of this device were to be described by Dr. Okita. These FET devices have since made it easier to insert into the true channel, to adjust its position adequately, to dilate the true channel, and to make the secured distal anastomosis for TAR, because all of them, particularly, Frozenix $^{\circledR}$, have different length and size variations. Early outcomes have shown improvement, with lower mortality and morbidity rates. In addition, regarding long-term outcomes, some impacts of FET have been addressed, such as higher incidence of down-stream aortic remodeling in the descending aorta and free-rate from aortic events, including secondary interventions for residual patent false lumens. Long-term survival would be expected through these positive findings.

However, after FET procedures, some related complications have been reported. Of them, the most serious is that of spinal cord injury (SCI). Between the late 1990s and the early 2000s, Japan saw a trend regarding prompt use of home-made OSG, instead of standard TAR. After inserting the OSG, SCI occurred frequently, at rates of $15-20 \%$, presumably due to long coverage of the intercostal arteries with long OSGs, causing embolization to the arteries responsible for spinal cord perfusion. Finally, this OSG trend dissipated in the recent era of thoracic 
endovascular aortic repair (TEVAR). Consequently, the positioning of the distal end of FET devices above the level of T8 is justified for prevention of SCI. The second issue involves another complication of stent graft-induced new entry (SINE). Through recent experiences, oversized FET devices and the mal-positioning of the distal end of FETs in the curved aortic segment, have been demonstrated as a risk-factor for SINE. For adequate use of Frozenix ${ }^{\circledR}$, a diameter of $25-27 \mathrm{~mm}(80-90 \%$ of the diameter of the targeted descending aorta in the pre-operative CT-scans) and a length of $9 \mathrm{~cm}$ for the zone 2 TAR procedure, are recommended to prevent these two serious complications.

In the recent 2015 and 2016 annual report of the Japanese Association for Thoracic Surgery $(9,10)$, the open aortic repairs for AAAD included root (-ascending) replacement in $7.0 \%$ of cases, ascending/hemi-arch replacement in $70.2 \%$, TAR (+ partial arch replacement, PAR) in $29.7 \%$, and root-arch replacement in $2.8 \%$ of cases. In 2016, FET procedures were added to the distal anastomosis of TAR in $47.7 \%$ of patients, while in most others, ET seemed to be used. Since 2014, the FET product device, Open Stent $\mathrm{Graft}^{\circledR}$ and Frozenix ${ }^{\circledR}$, has been made available. In the above nation-wide data of 2016, the use of FET was limited to less than $50 \%$ of TAR cases, however nowadays, it has been increased to over $80 \%$, in conjunction with TAR for AAAD (private communication).

Another issue involves the use of FET in AAAD for patients with connective tissue disorders, such as Marfan syndrome. For such patients with a fragile and thin aortic wall, limited use of TEVAR has been recommended. The use of FET here is also controversial. However, apart from TEVAR devices, Frozenix ${ }^{\circledR}$ has an internal stent, which may be safer for the fragile aorta. Additionally, TAR with FET has been indicated for primary entry closure in type B acute aortic dissection (AAD) (11).

In the recent era of prompt TEVAR for complicated cases, and a proportion of uncomplicated ones, the indication of TAR with FET would otherwise be limited; however complicated type B AAD with retrograde dissection into the arch or with arch dilatation/aneurysm, can be repaired through the antegrade approach of TAR with FET.

Finally, in the ongoing analyses of the Japanese multicenter study (not published) on TAR with FET (n=143) for AAAD, outcomes were favorable, with in-hospital mortality at $2.1 \%$, stroke in $7.7 \%$ of patients, and SCI in $3.5 \%$ of cases (paraplegia $2.1 \%$, paraparesis $1.4 \%$ ). Recent well-standardized TAR with FET conferring a lower
SCI rate should thus be increasingly indicated for further improvement of long-term outcomes.

\section{Acknowledgments}

None.

\section{Footnote}

Conflicts of Interest: The author has no conflicts of interest to declare.

Open Access Statement: This is an Open Access article distributed in accordance with the Creative Commons Attribution-NonCommercial-NoDerivs 4.0 International License (CC BY-NC-ND 4.0), which permits the noncommercial replication and distribution of the article with the strict proviso that no changes or edits are made and the original work is properly cited (including links to both the formal publication through the relevant DOI and the license). See: https://creativecommons.org/licenses/by-nc-nd/4.0/.

\section{References}

1. Kato M, Kuratani T, Kaneko M, et al. The results of total arch graft implantation with open stent-graft placement for type A aortic dissection. J Thorac Cardiovasc Surg 2002;124:531-40.

2. Kazui T, Washiyama N, Muhammad BA, et al. Extended total arch replacement for acute type a aortic dissection: experience with seventy patients. J Thorac Cardiovasc Surg. 2000;119:558-65.

3. Watanuki $\mathrm{H}$, Ogino $\mathrm{H}$, Minatoya $\mathrm{K}$, et al. Is emergency total arch replacement with a modified elephant trunk technique justified for acute type A aortic dissection?. Ann Thorac Surg 2007;84:1585-91.

4. Ishihara $\mathrm{H}$, Uchida $\mathrm{N}$, Yamasaki $\mathrm{C}$, et al. Extensive primary repair of the thoracic aorta in Stanford type A acute aortic dissection by means of a synthetic vascular graft with a self-expandable stent. J Thorac Cardiovasc Surg 2002;123:1035-40.

5. Uchida $\mathrm{N}$, Ishihara $\mathrm{H}$, Shibamura $\mathrm{H}$, et al. Midterm results of extensive primary repair of the thoracic aorta by means of total arch replacement with open stent graft placement for an acute type A aortic dissection. J Thorac Cardiovasc Surg 2006;131:862-7.

6. Tsagakis K, Pacini D, Di Bartolomeo R, et al. Multicenter early experience with extended aortic repair in acute aortic 
dissection: is simultaneous descending stent grafting justified?. J Thorac Cardiovasc Surg 2010;140:S116-46. discussion S142-6.

7. Sun L, Li M, Zhu J, et al. Surgery for patients with Marfan syndrome with type A dissection involving the aortic arch using total arch replacement combined with stented elephant trunk implantation: the acute versus the chronic. J Thorac Cardiovasc Surg 2011;142:e85-91.

8. Shrestha M, Haverich A, Martens A. Total aortic arch replacement with the frozen elephant trunk procedure in acute DeBakey type I aortic dissections. Eur J Cardiothorac Surg 2017;51:i29-34.

9. Committee for Scientific Affairs, The Japanese Association for Thoracic Surgery, Shimizu H, et al. Thoracic and

Cite this article as: Ogino $\mathrm{H}$. Acute type A aortic dissection: the role of frozen elephant trunk. Ann Cardiothorac Surg 2020;9(3):233-235. doi: 10.21037/acs-2019-fet-19 cardiovascular surgery in Japan in 2016 : Annual report by The Japanese Association for Thoracic Surgery [published correction appears in Gen Thorac Cardiovasc Surg 2019;67:573-5]. Gen Thorac Cardiovasc Surg 2019;67:377-11.

10. Shimizu H, Hirahara N, Motomura N, et al. Current status of cardiovascular surgery in Japan, 2015 and 2016: analysis of data from Japan Cardiovascular Surgery Database. 4-Thoracic aortic surgery. Gen Thorac Cardiovasc Surg 2019;67:751-7.

11. Uchida N, Katayama A, Tamura K, et al. Early entry closure for acute type B aortic dissection by open stent grafting. Gen Thorac Cardiovasc Surg 2011;59:329-34. 